\title{
Gender Differences in Major Selection and Academic Success for Students Leaving Engineering
}

\author{
Guili Zhang, Miguel A. Padilla, and Timothy J. Anderson \\ Educational Statistics and Chemical Engineering, University of Florida \\ Matthew W. Ohland, General Engineering, Clemson University
}

\begin{abstract}
The major selection and academic performance of students who matriculated in and subsequently left undergraduate engineering programs are studied at the nine SUCCEED universities (Southeastern University and College Coalition for Engineering Education) from 1987 to 1996 (requiring student data from 1987 to 2002) to determine gender differences in these outcomes. Academic success after leaving engineering is characterized by three outcomes: graduation in the first non-engineering major, graduation after at least one additional change of major, and failure to graduate. The impact of gender and grade-point average (GPA) at the time of leaving engineering on major selection and subsequent academic success were investigated in a multicategory, logistic regression model. The results revealed a significant interaction effect between GPA and gender on students' post-engineering success. Females leaving engineering with GPA less than 2.65 were more likely to graduate in the first non-engineering major. At higher GPA's, the reverse was true. Females who changed their major at least once more were also more likely to graduate than their male counterparts when leaving engineering with lower GPA (less than 2.75), the difference is not observed for males and females leaving engineering with GPA greater than 2.75. Concomitant to these two success rates is that females with a GPA lower than 2.8 are more likely to graduate after leaving engineering than their male counterparts. With a GPA greater than 3.125, males were more likely to graduate after leaving engineering than females. With GPA between 2.8 and 3.125, males and females had the same probability of graduation after leaving engineering.
\end{abstract}

\section{Introduction}

Understanding major selection and academic success among engineering students who leave engineering for other disciplines can lend useful information to various people who have an interest in or are affected by such an academic phenomena. It is intuitive that a student's academic success prior to leaving engineering (such as grade-point average) has some impact on whether they leave engineering as well as that student's post-engineering academic success. In fact, many research studies have explored these relationships. In a landmark study, Astin showed that majoring in engineering had a negative effect on both grade-point average and chance of graduation. ${ }^{1}$ Seymour and Hewitt documented a three-year study in which they interviewed students about their decision to leave the sciences. ${ }^{2}$ While there were no major differences among different types of institutions in regard to the problems described by their students, students at all types of institutions cited structural or cultural reasons, lack or loss of interest, poor teaching, and pace and workload concerns. Besterfield-Sacre and colleagues studied the predictive value of freshman engineering attitudes.$^{3-4}$ Other studies build on these in studies of students at a single institution or multiple institutions. ${ }^{5-8}$ 
However, a number of questions remain unanswered:

1. Does GPA prior to leaving engineering have an impact on students' decision of leaving engineering and choice of destination major?

2. How much does GPA prior to leaving engineering influence students success in subsequent destination major?

3. Do some other factors such as gender play a role in the phenomena? Is there a tendency for male and female students to select different post-engineering majors even if they have similar grade points? To what extent does gender moderate the impact of grade-point average on academic success?

This study aims to answer these questions using descriptive statistics and a multi-category logistic regression model on longitudinal data from nine SUCCEED universities.

\section{Data}

Our study uses the Southeastern University and College Coalition for Engineering Education (SUCCEED) longitudinal database (LDB). The LDB contains data from eight colleges of engineering involving nine universities: Clemson University, Florida A\&M University, Florida State University, Georgia Institute of Technology, North Carolina A\&T State University, North Carolina State University, University of Florida, University of North Carolina at Charlotte and Virginia Polytechnic Institute and State University. The data from all nine universities have been placed in a common format, making it possible to carry out appropriate cross-institutional studies. The SUCCEED LDB is a unique resource that has been and continues to be studied, and is representative of a large cross-section of undergraduate engineering education. ${ }^{9-25}$ While the LDB contains data on both transfer students as well as first-time-in-college (FTIC) students, we limited the study to FTIC students only.

Among the demographic information, gender information was available for virtually every student record. Grade-point averages are frozen at the time students leave engineering to investigate the role of GPA in their decision to leave engineering and their choice of a destination major as well as the relationship between GPA and subsequent post-engineering success. Term and graduation data permit us to examine performance indicators such as when and how many times a student changed major, and whether a student graduated as well as in what discipline a student graduated. This information was complete for all institutions and virtually every student record.

\section{Statistical Analysis}

Descriptive statistics are obtained to provide the following information:

1. The GPA distribution of female and male students leaving engineering at the time of major switching.

2. Disciplines into which male and female students change.

3. Impact of GPA on choice of disciplines.

4. Disciplines in which male and female students graduate. 
In addition, a series of five nested multi-category logistic regression models ${ }^{26}$ were formed to test for the significance of the following three factors on graduation probability: GPA, gender, and the interaction between GPA and Gender. If Model B's predictors are a subset of the predictors in Model A, then Model B is said to be nested in Model A. The outcome variable graduation is modeled to assume three possible values: graduate in first non-engineering major, graduate after changing major again, and do not graduate. Let $\pi_{1}$ be the probability of graduation in the first non-engineering major, $\pi_{2}$ be the probability of graduation after changing major again, and $\pi_{3}$ be the probability of failure, the five models have the following two general equations with Model 1 being the full model (incorporating all three predictors):

$$
\begin{aligned}
& \log \left(\frac{\pi_{1}}{\pi_{3}}\right)=\beta_{01}+\beta_{11} \times \text { Gender }+\beta_{21} \times G P A+\beta_{31} \times \text { Gender } * G P A+\varepsilon \text { and } \\
& \log \left(\frac{\pi_{2}}{\pi_{3}}\right)=\beta_{02}+\beta_{12} \times \text { Gender }+\beta_{22} \times G P A+\beta_{32} \times \text { Gender } * G P A+\varepsilon
\end{aligned}
$$

If Model 1 represents the data, it must fit better than any of four reduced models shown for comparison in Table 1.

Table 1. Predictors included in each of the five multicategory logistic regression models

\begin{tabular}{|l|c|c|c|}
\hline & Gender & GPA & Gender $\times$ GPA \\
\hline Model 1 (full model) & $\mathrm{x}$ & $\mathrm{x}$ & $\mathrm{x}$ \\
\hline Model 2 (GPA and gender) & $\mathrm{x}$ & $\mathrm{x}$ & \\
\hline Model 3 (gender only) & $\mathrm{x}$ & & \\
\hline Model 4 (GPA only) & & $\mathrm{x}$ & \\
\hline Model 5 (null) & & & \\
\hline
\end{tabular}

Such a series of models enable us to compare model fit statistics between any two nested models and determine whether a certain predictor has significant effect on graduation. For example, if Model 1 fits the data significantly better than Model 2, we would conclude that the extra predictor in Model 1 (the interaction effect) contribute significantly to better describing the data. On the other hand, if Model 1 does not fit the data significantly better than Model 2, we would conclude that the extra predictor in Model 1 is trial and not needed in the model, and Model 2 fits the data adequately. The significance of difference in model fits is determined by log likelihood ratio test. The model estimates will enable us to produce the estimated probability of success as a function of gender and GPA.

\section{Results}

\section{GPA distribution of male and female students leaving engineering}

Based on data available in the LDB, 10,905 engineering students left engineering for another discipline during the time period from 1987 and 1996. Among the 10,905 students, 8,022 are males and 2,883 are females. The GPA distribution of female and male students leaving engineering as shown in Figure 1 reveals that a majority of students leaving engineering within the subpopulation of each gender have a cumulative GPA of 1.5 to 3.0, but many leave with a 
cumulative GPA greater than 3.0. More importantly, it is noted that the GPA distribution for females leaving engineering is very similar to that of males. Upon closer inspection, it is noted that females that leave engineering have a higher GPA than their male counterparts - the percentage of females is greater in each GPA range greater than 2.5.

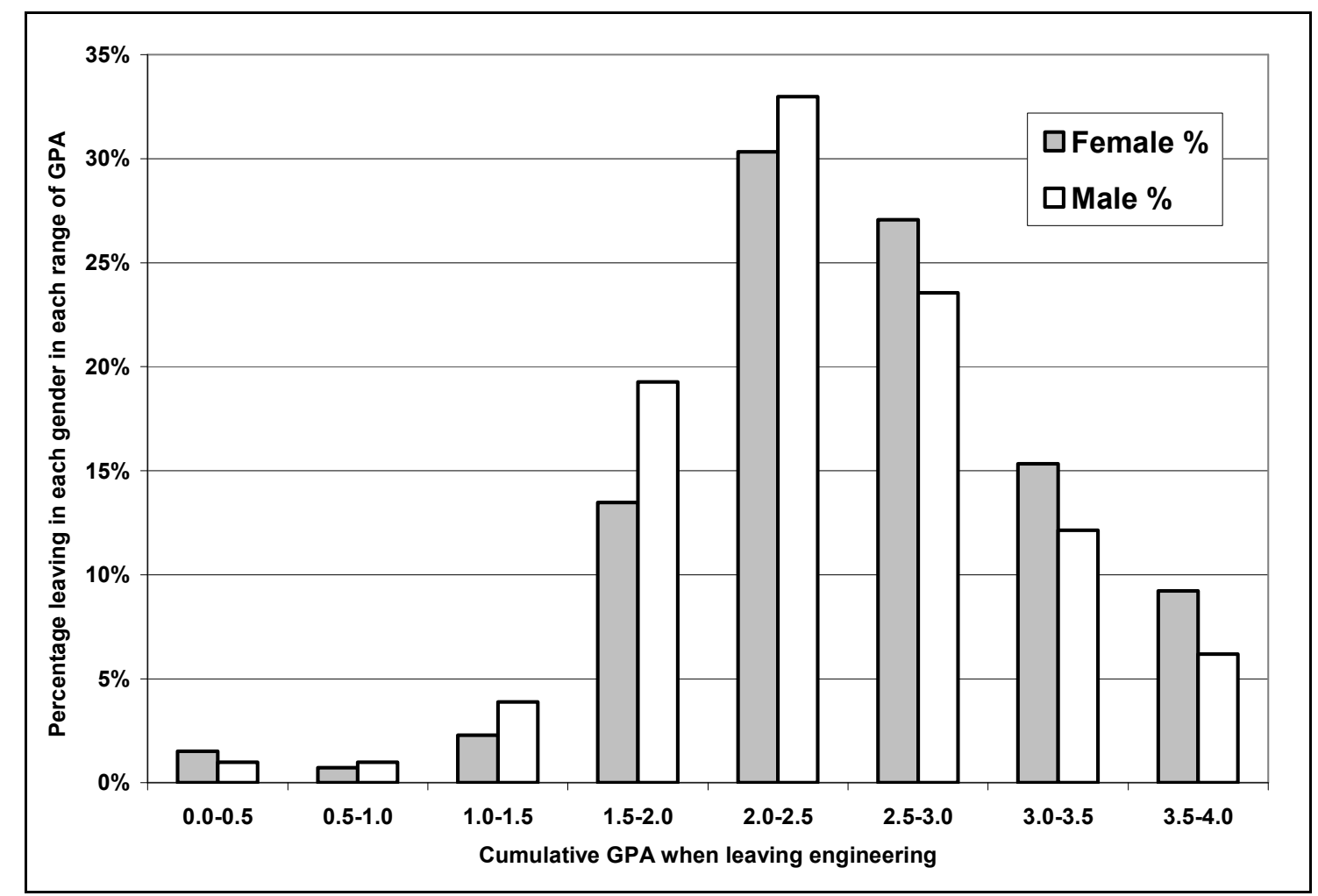

Figure 1. Percentage of Students Leaving Engineering by GPA Range by Gender

\section{Disciplines male and female students major in after leaving engineering}

There are seven disciplines (as shown in Figure 2) that attract 3\% or more of students leaving engineering, accounting for over $68 \%$ of all students leaving engineering. The rest of the students, approximately $32 \%$ of all students leaving engineering, are scattered into 24 other disciplines, with less than $3 \%$ of students choosing each major. There are notable similarities and differences in female and male students' choice of disciplines. Both female and male students are most likely to major in business after leaving engineering. About one third of students of both genders changes to a discipline other than the seven mainstream disciplines reported. Females leaving engineering are more likely than males to major in biology, physics, education, and math than male students. Male students were more likely than females to choose business, computer science, and social science. Notably, males are more than twice as likely as females to choose computer science when leaving engineering. Females were twice as likely as males to choose biology and education, but males were 1.5 times as likely as females to choose one of the social sciences. Specifically, males are three times as likely as females to choose History and twice as likely to choose Anthropology, Economics, and Political Science. Furthermore, males dominated those who choose Geography. The percentages of males and females who choose International Relations and Affairs are similar, and a slightly lower percentage of males than females choose Sociology. 


\section{The relationship of GPA and choice of disciplines}

The relationship of GPA and the disciplines students choose to major in when they leave engineering has been studied previously. This relationship is similar for female and male students. As shown in Figure 2, both females and males are more likely to major in business and less likely to major in the sciences if they leave engineering with a low GPA. Both females and males are less likely to select business and more likely to select the sciences at higher GPAs. As observed in our earlier work, the percentage of females and males selecting education and the social sciences is $10-20 \%$ across the entire range of GPA when leaving engineering. In looking at the data with social sciences separate from education, it is noted that the percentage changing into social sciences decreases at higher levels of GPA. Education, on the other hand, attracts a similar percentage of students, both female and male, across all GPA ranges.

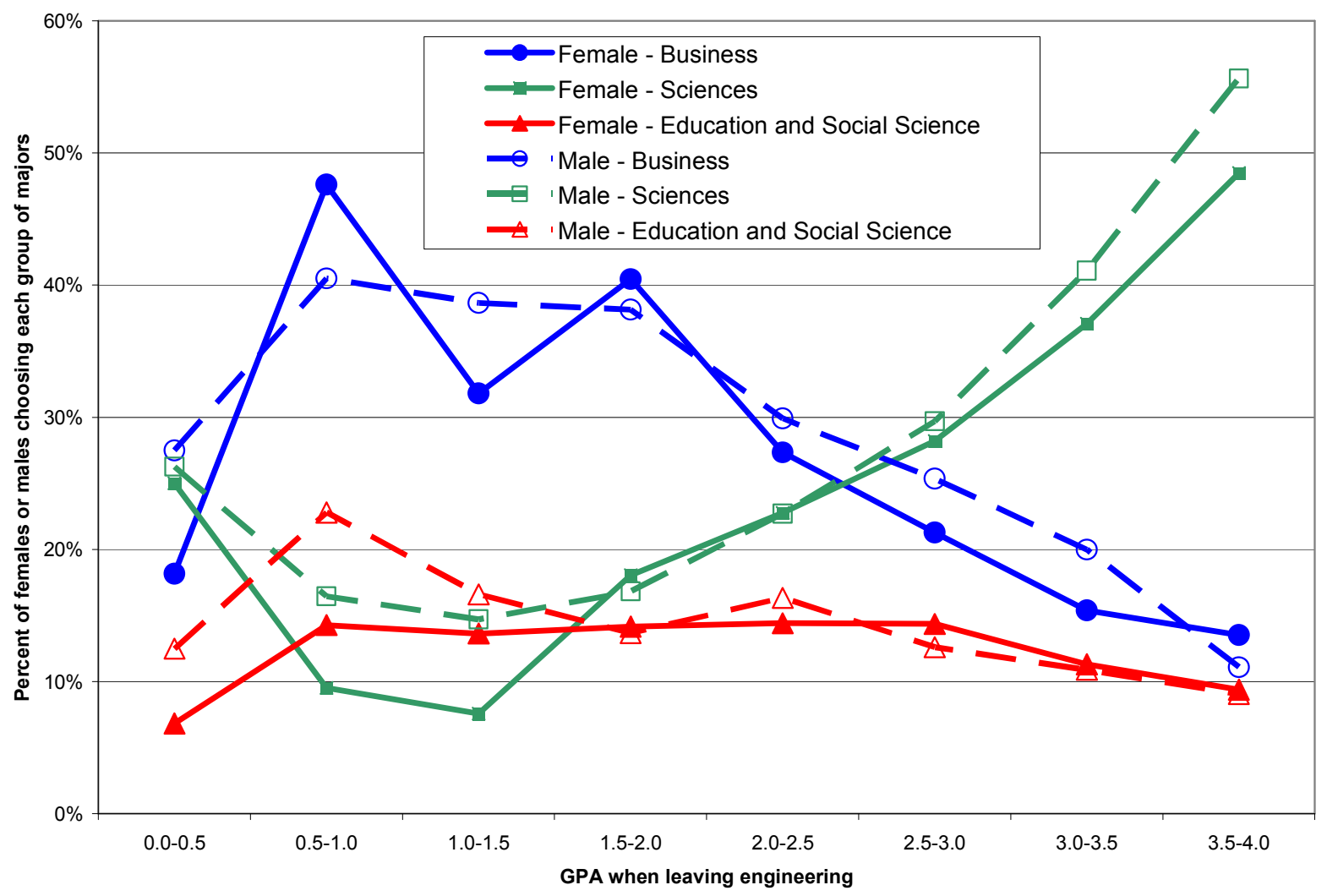

Figure 2. The relationship of GPA and major selected by females and males leaving engineering $(\mathrm{N}=2,883$ female, 8,022 male).

\section{The graduation rates in various disciplines}

Graduation data also show some similarities and differences between female and male students. Slightly over two thirds (68.7\%) of students leaving engineering graduate within six years of their initial matriculation date. When looking at graduation rates in Figure 3, we see that both female and male students have high graduation rates in business. Females leaving engineering are more likely to graduate than males in all disciplines except for computer science, which few females select. We learned earlier in this paper that females were twice as likely as males to major in education when leaving engineering, and here we discover that females selecting 
education are also more likely to graduate there than males. Females leaving engineering for mathematics are much more likely to graduate there than males.

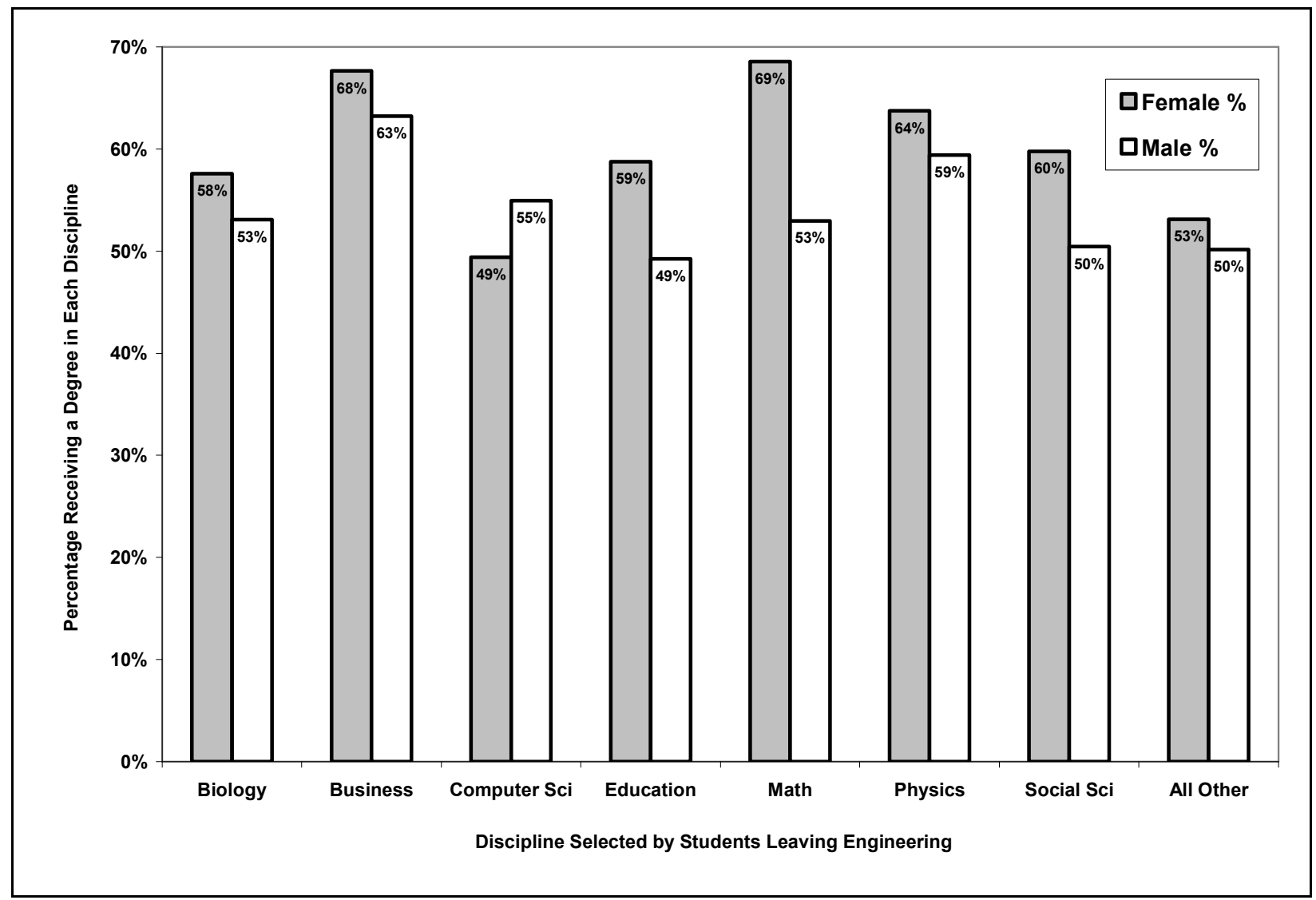

Figure 3. The percentage of students graduating in selected disciplines of those selecting each major upon leaving engineering $(\mathrm{N}=2,883$ female, 8,022 male).

\section{Estimated Probability of Success as a Function of Gender and GPA}

The multi-category logistic regression models bear out a significant interaction effect between GPA and gender variables. Parameter estimates yielded by the models enable us to formulate the following projected probabilities of having each of the three graduation outcome for female and male students respectively, as a function of student's gender and cumulative GPA.

The probability that a female will graduate in first non-engineering major:

$$
\pi_{\mathrm{F} 1}=\frac{\exp (-.9074+.6546 \times G P A)}{1+\exp (-.9074+.6546 \times G P A)+\exp (-2.1648+.599 \times G P A)}
$$

The probability that a female will graduate after changing major again:

$$
\pi_{\mathrm{F} 2}=\frac{\exp (-2.1648+.599 \times G P A)}{1+\exp (-.9074+.6546 \times G P A)+\exp (-2.1648+.599 \times G P A)}
$$

The probability that a female will fail to graduate:

$$
\pi_{\mathrm{F} 3}=\frac{1}{1+\exp (-.9074+.6546 \times G P A)+\exp (-2.1648+.599 \times G P A)}
$$


The probability that a male will graduate in first non-engineering major:

$$
\pi_{\mathrm{M} 1}=\frac{\exp (-1.6228+.9109 \times G P A)}{1+\exp (-1.6228+.9109 \times G P A)+\exp (-3.1279+.9093 \times G P A)}
$$

The probability that a male will graduate after changing major again:

$$
\pi_{\mathrm{M} 2}=\frac{\exp (-3.1279+.9093 \times G P A)}{1+\exp (-1.6228+.9109 \times G P A)+\exp (-3.1279+.9093 \times G P A)}
$$

The probability that a male will fail to graduate:

$$
\pi_{\mathrm{M} 2}=\frac{1}{1+\exp (-1.6228+.9109 \times G P A)+\exp (-3.1279+.9093 \times G P A)}
$$

Figure 4 graphically shows the model projected probabilities of success outcome for students leaving engineering as a function of gender and cumulative GPA. An interaction is present when the effect of one variable on the outcome variable varies across the level of another variable. While there are similarities among the behaviors of females and males, Figure 4 shows a GPA by Gender interaction effect. Among students with a cumulative GPA of 2.65 or higher, the probability that a male student will graduate in the first non-engineering discipline is roughly $2 \%$ higher than that of a female. However, among students with a cumulative GPA of 2.65 or lower, the probability that a male student will graduate in the first non-engineering discipline is between $1 \%$ and $10 \%$ lower than his female counterpart. With a GPA of 1.5 or lower, female students probability of graduation in the first non-engineering discipline is consistently close to $10 \%$ higher than that of the males. With a cumulative GPA of 2.75 or higher, the probability that female and male students graduate after changing major again is virtually the same. However, with a cumulative GPA lower than 2.75, females' probability of graduation after changing major again is higher than males'. Not surprisingly, both male and female students' probability of failure decreases as cumulative GPA increases. As observed in our earlier work, the percentage of females and males graduating after changing majors at least one more time varies from 5-15\% over the entire range of GPA. The model shows a difference between females and males in this as well - in addition to being more likely to graduate in their first choice of major after leaving engineering, females are also more likely to graduate after changing majors again. This is most significant at the lower limits of GPA - the model would predict that females with the lowest of GPAs (0-0.25) are nearly twice as likely to graduate as males (34\% vs. 19\%) after leaving engineering. 


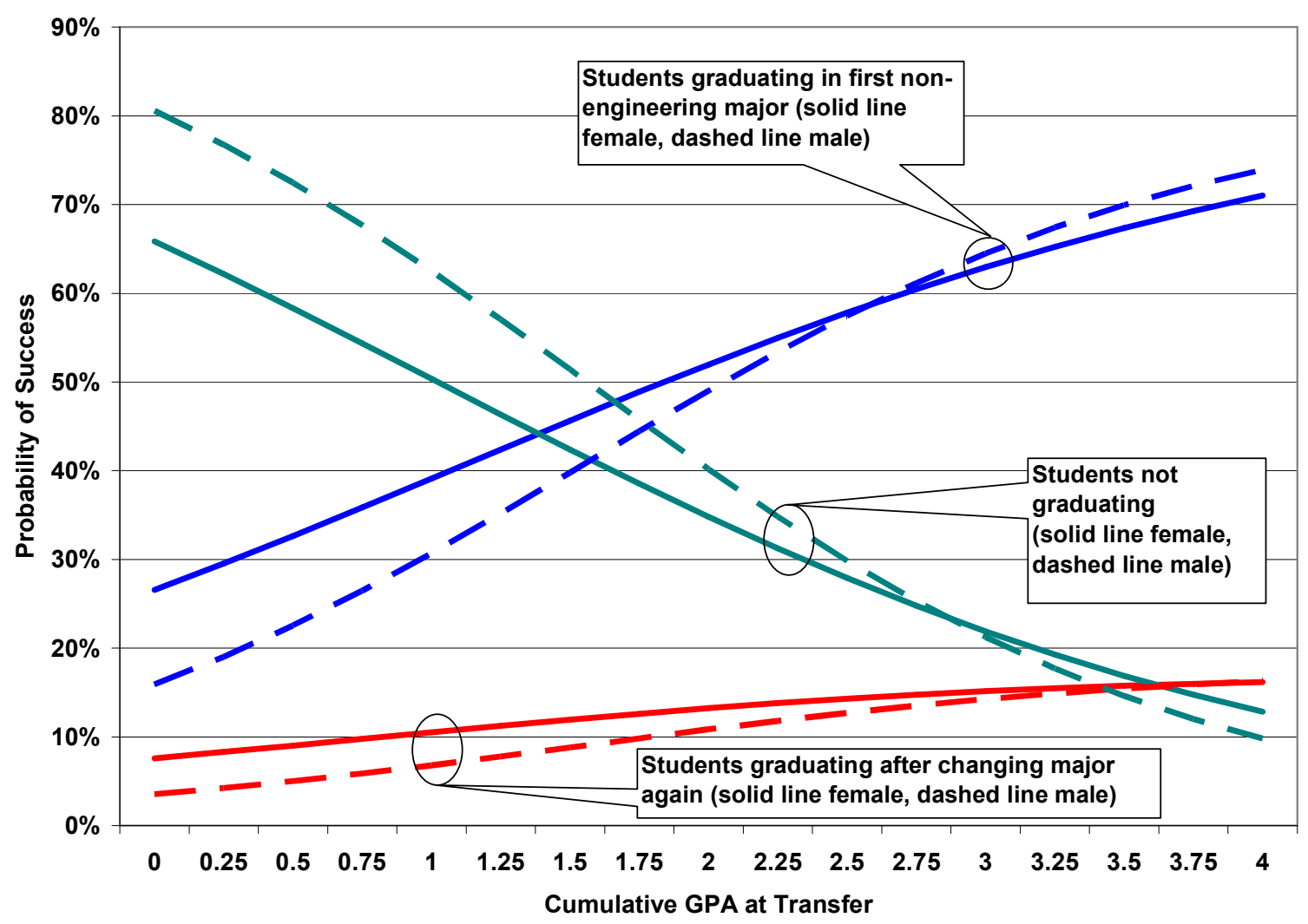

Figure 4. Calculated model probability of various graduation outcomes for female and male students related to GPA when leaving engineering.

\section{Discussion}

Among the 10,905 students who left engineering for another major during the period of this study, 8,022 (74\%) are male and 2,883 (26\%) are female. It is already known that females are underrepresented among students matriculating to engineering-in recent years, engineering colleges have found it difficult to matriculate populations that are greater than $20 \%$ female. It is also known that those leaving engineering are disproportionately female-since more than $20 \%$ of those leaving engineering are female. If a 100 -student cohort with a $60 \%$ retention rate in engineering had the rates of gender departure above, the graduating class would be $83 \%$ male (50 students) and 17\% female (10 students). While the overrepresentation of females among those leaving engineering worsens the gender gap, the matriculation gap is clearly the dominant issue. Our earlier study reinforced Adelman's message that academic performance is not the primary reason that students leave engineering. ${ }^{27}$ This is even more notable for female students, who leave engineering with higher grades on average than males. This suggests that a higher percentage of female students leave engineering for other reasons, but that is not necessarily the case. Seymour and Hewitt's findings indicate that while many engineering students receive grades below their expectations, females are more likely to leave engineering in response to those mismatched expectations. ${ }^{3}$ Therefore, even though females tend to have higher GPAs when 
leaving engineering, they may still be leaving engineering because they are dissatisfied with their grades.

The percentage changing into Computer Science, Biology, Physics, and Math increases as GPA increases, revealing a strong dependency between GPA level and decision to move into these disciplines. This is likely related to the success that students with higher GPAs are already having in the courses required for these majors. The fact that the graduation rates are high for students selecting business as a major when they leave engineering may be an important reason so many students choose that major, as discussed in our earlier work. The low number of females leaving engineering that choose computer science and the lower graduation rate of those who do choose it are reminders that computer science programs share with engineering the challenge of maintaining a gender-diverse population-it is difficult to attract females to computer science and retain them even when the females are coming from a pre-selected group that started in engineering.

We are very intrigued by the gender and GPA interaction illustrated in Figure 1-female students with low GPAs $(<2.5)$ have a much higher probability of success than males with similar GPAs. The implications on advising practices are obvious and a better understanding of the underlying reasons for this pattern might alter our approach to reducing the gender gap. Future research should include qualitative assessment to help understand why female students respond more positively to poor grades. Considering the gender differences that Seymour and Hewitt point out in how low grades are interpreted, do females earning low grades work harder out of a need to validate themselves? Is this disproportionate success rate at lower levels of GPA related to Attention-Deficit/Hyperactivity Disorder (ADHD), which is more common among males (about two and a half times more likely to have been diagnosed than females) ${ }^{28}$ There may also be relationships with time in the program or with performance in certain course groupings or by discipline or institutional setting. The database is currently being expanded to include course level information that will allow a more complete quantitative analysis.

\section{Author biographies}

\section{GUILI ZHANG}

is a Ph.D. candidate in Educational Research and Statistics, Department of Educational Psychology, University of Florida. She received a B.A. in British and American Language and Literature at Shandong University, China, and a M.Ed. in English Education at Georgia Southern University. She has published extensively and has won numerous awards at the national and regional level in the area of educational research in China. She teaches Measurement and Assessment in Education at the University of Florida. Her research interests involve applied quantitative research designs, categorical data analysis, and structural equation modeling.

MIGUEL A. PADILLA

is a Ph.D. candidate in Educational Research and Statistics, Department of Educational Psychology, University of Florida and previously received an M.A. from that program. He received a B.A. in Psychology from California State University, Domingus Hills.

\section{TIMOTHY J. ANDERSON}

is Associate Dean for Research and Graduate Programs in the College of Engineering, and Professor in the Department of Chemical Engineering, University of Florida. He received a Ph.D. at the University of CaliforniaBerkeley in 1979. His research interests include electronic materials processing, thermochemistry and phase diagrams, chemical vapor deposition, bulk crystal growth and advanced composite materials. 
MATTHEW W. OHLAND

is Assistant Professor in General Engineering at Clemson University and is the President of Tau Beta Pi, the national engineering honor society. He received a Ph.D. in Civil Engineering with a minor in Education from the University of Florida in 1996. He previously served as Assistant Director of the NSF-sponsored SUCCEED Engineering Education Coalition. His research is in freshman programs and educational assessment.

\section{References}

[1] Astin, A.W. (1971) Predicting Academic Performance in College, The Free Press, New York.

[2] Seymour, E., and Hewitt, N. M. (2000) Talking About Leaving: Why Undergraduates Leave the Sciences, Westview Press.

[3] Besterfield-Sacre, M., Moreno, M., Shuman, L. and Atman, C. (2001) "Gender and Ethnicity Differences in Freshmen Engineering Student Attitudes: A cross-Institutional Study," Journal of Engineering Education, October, pp. 477-489.

[4] Besterfield-Sacre, M., Atman, C., and Shuman, L. (1997) "Characteristics of Freshman Engineering Students: Models for Determining Student Attrition in Engineering," Journal of Engineering Education, April, pp. 139149.

[5] Ohland, M. W., Zhang, G., Thorydyke, B., and Anderson, T. J. (2004) "Grade-Point Average, Changes of Major, and Majors Selected by Students Leaving Engineering," in press Proc. Frontiers in Education 2004, Savannah, Georgia, November, 2004, paper 1478.

[6] Zhang, Z. and RiCharde, R.S. (1998) "Prediction and Analysis of Freshman Retention," AIR 1998 Annual Forum Paper, Minneapolis, MN.

[7] Levin, J. and Wyckoff, J. (1990) "Identification of Student Characteristics that Predict Persistence and Success in an Engineering College at the End of the Sophomore Year: Informing the Practice of Academic Advising," Division of Undergraduate Studies Report No. 1990.1, Pennsylvania State University.

[8] Moller-Wong, C. and Eide, A. (1997) “An Engineering Student Retention Study," Journal of Engineering Education, January, pp. 7-15.

[9] Padilla, M.A., G. Zhang, T.J. Anderson, and M.W. Ohland, "Drawing Valid Inferences from the Nested Structure of Engineering Education Data: Application of a Hierarchical Linear Model to the SUCCEED Longitudinal Database," Proc. Amer. Soc. Eng. Ed., Portland, Oregon, June 2005.

[10] Ohland, M.W., G. Zhang, S.A. Frillman, C.E. Brawner, and T.K. Miller, "The Effect of an Entrepreneurship Program on GPA and Retention," in press, J. Eng. Ed. 93(4), October 2004.

[11] Zhang, G., T.J. Anderson, M.W. Ohland, R. Carter, and B. Thorndyke, "Identifying Factors Influencing Engineering Student Graduation and Retention: A Longitudinal and Cross-Institutional Study," in press, J. Eng. Ed. 93(4), October 2004.

[12] Ohland, M.W., G. Zhang, B. Thorndyke, and T.J. Anderson, "The creation of the Multiple-Institution Database for Investigating Engineering Longitudinal Development (MIDFIELD)" Proc. Amer. Soc. Eng. Ed., Salt Lake City, Utah, June 2004.

[13] Zhang, G., B. Thorndyke, M.W. Ohland, T.J. Anderson, "How do Science Courses Influence Engineering Student Retention - A Statistical Investigation” Proc. Amer. Soc. Eng. Ed., Salt Lake City, Utah, June 2004.

[14] Ohland, M.W., S.A. Frillman, G. Zhang, and T.K. Miller, "NC State's Engineering Entrepreneurs Program in the Context of U.S. Entrepreneurship Programs" NCIIA 8th Annual Meeting: Education that Works: Invention, Innovation, and Entrepreneurship in Practice, San Jose, California, March 18-20, 2004.

[15] Zhang, G., B. Thorndyke, R. Carter, T.J. Anderson, and M.W. Ohland, "How do Chemical Engineering Students Differ from Others?” Proc. Amer. Soc. Eng. Ed., Nashville, Tennessee, June 2003. Received Best Paper Award (one of five at Conference).

[16] Ohland, M.W., R.M. Felder, M.I. Hoit, G. Zhang, and T.J. Anderson, "Integrated Curricula in the SUCCEED Coalition,” Proc. Amer. Soc. Eng. Ed., Nashville, Tennessee, June 2003. 
[17] Ohland, M.W., G. Zhang, C.E. Brawner, T.K. Miller, III, "A Longitudinal Study of Retention and Grade Performance of Participants in an Engineering Entrepreneurs Program," Proc. Amer. Soc. Eng. Ed., Nashville, Tennessee, June 2003.

[18] Zhang, G., R. Carter, B. Thorndyke, T.J. Anderson, and M.W. Ohland, "A Comparison of Demographic Factors and Academic Performance between Students Graduated in Engineering and Other Disciplines," Proc. Amer. Soc. Eng. Ed., Nashville, Tennessee, June 2003.

[19] Zhang, G., R. Carter, B. Thorndyke, T.J. Anderson, and M.W. Ohland, "Are Engineering Students Different from Others?" Proc. Amer. Soc. Eng. Ed. Southeast, 2003.

[20] Anderson, T., R. Carter, M. Ohland, B. Thorndyke, and Guili Zhang, "Identifying Factors Influencing Engineering Student Graduation and Retention through a Longitudinal and Cross-Institutional Study," Proc. Amer. Soc. Eng. Ed., Montreal, Canada, June 2002.

[21] Zhang, G., T.J. Anderson, M.W. Ohland, R. Carter, and B. Thorndyke, "Identifying Factors Influencing Engineering Student Graduation and Retention: A Longitudinal and Cross-Institutional Study," Proc. Amer. Soc. Eng. Ed Southeast., Gainesville, FL, April 2002, Session 2793.

[22] Ohland, M.W., and S.A. Rajala, and T.J. Anderson, "SUCCEED-Sponsored Freshman Year Engineering Curriculum Improvements at NC State: A Longitudinal Study of Retention," Proc. Amer. Soc. Eng. Ed., Albuquerque, NM, June 2001.

[23] Ohland, M.W., G. Zhang, F.J. Foreman, and F. Haynes, "The Engineering Concepts Institute: The Foundation of a Comprehensive Minority Student Development Program at the FAMU-FSU College of Engineering," Proc. Frontiers in Education, Kansas City, MO, October, 2000, paper 1372.

[24] Ohland, M.W., and T.J. Anderson, "Studying the Contribution of Programs at Eight Engineering Colleges toward Student Success," FIE 1999, San Juan, Puerto Rico, November 10-14, 1999, proceedings, 1 page.

[25] Ohland, M.W., and T.J. Anderson, "Studying the Contribution of Programs at Eight Engineering Colleges toward Student Success," International Conference on Engineering Education 1999, Ostrava and Prague, Czech Republic, August 8-14, 1999, published in proceedings on CD-ROM, paper 436, 9 pages (indexed by the ERIC database with accession number ED452047).

[26] Agresti, A. (1996) An Introduction to Categorical Data Analysis, John Wiley \& Sons, Inc., New York.

[27] Adelman, Clifford. (1998) Women and Men of the Engineering Path: A Model for Analyses of Undergraduate Careers. U.S. Department of Education, PLLI-98-8055. Available at http://www.erc-assoc.org/nsf/engrg_paths/

[28] Dunn, David W., Joan K. Austin, Jaroslaw Harezlak, and Walter T. Ambrosius (2003), “ADHD and epilepsy in childhood," Developmental Medicine \& Child Neurology 45, 50-54. 